\title{
COMMUNITY PARTICIPATION AND EDUCATION ON HERITAGE SITES: A NEW \\ ERA OF COLLECTIVE ACCOUNTABILITY IN ZIMBABWEAN HERITAGE \\ MANAGEMENT FOCUSING ON MUSIMBIRA HERITAGE SITE, BIKITA
}

\section{$\underline{\text { Abstract }}$}

Community participation is one of the best ways to ensure that heritage sites are well managed and conserved. This can only, however, be achieved in a scenario where the community in question has an adequate understanding of what they should be managing i.e. the broader spectrum of their heritage. Such understanding can be induced through community education campaigns and community-based heritage-managed systems. These and other methods have been considered given the fact that colonial structures have resulted in the alleged "brainwashing" of the natives on the usefulness of their heritage, thereby resulting in them neglecting their heritage. It is in this regard that, the NMMZ (National Museums and Monuments of Zimbabwe) being in charge of the management of heritage sites in Zimbabwe has been witnessed taking certain measures to ensure that heritage is well managed. However such efforts have in many cases gone in vain because of the NMMZ's failure to fully recognize the communities in their management strategies. "Such blunders by the organization" have thus resulted in the conflict of interests between the organization and the communities. Telephone interviews, field individual observations, and a focus group discussion were conducted as data collection methodologies. Therefore it was concluded in this paper that, Interpretation of the site and awareness through educational campaigns enables the first phase towards heritage conservation to be highly achievable, in the case of Musimbira ruins. Hence conservation being a broad term cannot be achieved only by one group of stakeholders but by different groups. It is again given in this paper, with Musimbira ruins as the present study area that educating as well as including communities close to different cultural heritage sites is one of the best heritage management strategies

Keywords: Musimbira, Zimbabwe, Education, Conserved, Management, Cultural heritage 


\section{Introduction}

It is an undisputed fact that colonization has resulted in the natives having negative perceptions concerning their heritage (e.g. Pwiti 1999). But such a mentality of continuously blaming the aftermath of colonization without any vibrant actions being put in place, cannot be used as an excuse for the deteriorating nature of Zimbabwe's cultural heritage. From various literature reviews, observations as well as interviews conducted for this study it became so apparent that NMMZ (National Museums and Monuments of Zimbabwe) is not doing enough justice in involving different stakeholders most importantly the community heritage management aspects. Indeed colonization created structures in which the natives were not given opportunities to participate in the management of their heritage. Ndoro (2001) argues that the process of colonization into Zimbabwe led to the western-style of heritage conservation. Such a style of heritage conservation has not been adequately revised since the inception of independence (see. Thondhlana and Machiridza 2020; Sagiya 2019; Makuvaza 2014; Chirikure and Pwiti 2008 e.t.c). This paper looks at Musimbira national monument in the northern edge of Bikita, as a site whose management is highly administrative and local people are not even aware of the importance of this site to them, while others are not even aware of its existence. It should be reminded that such a management style and system have resulted in a poor state of the heritage site's appearance. Sound management of such sites, therefore, requires day-to-day monitoring and direct management of the site which can only be achieved if the community is included. This paper, therefore, argues that communities should be educated and actively involved in the management of their heritage. This is because it's preservation or destruction affects both the present and future generations. Management of these properties without the community's active involvement and knowledge disregards the sustainable use of these sites, while it also detaches man from his roots/ancestors and pride.

\section{Data collection methods}

Individuals selected for telephone interviews were chosen as the long-time residents of the area close to the site, hence were perceived to have amble knowledge of the conservation activities which to place over time. Eight youths from within the community close to the Musimbira site were also selected for a focus group discussion. The sampling procedure applied to the selection of the youths was intuitive random sampling targeting both university, high school students, and 
the working class. In this case, sampling was based upon the educational and occupational backgrounds of the youths. This was done to understand the perceptions of the existence of such sites to the potential future leaders from the community

\section{An overview of dry stone wall Heritage Sites in Zimbabwe}

In Mawere et al (2012)'s words the concept of "heritage sites" is well understood and defined for practical and philosophical reasons and according to one's background. Therefore in this regard, the concept of heritage sites has no universal definition. The Collins English dictionary (1994), on one hand, defines a heritage site, as a historical site, a building, or an area of undisturbed environment, considered, to be important to a country or area's heritage. The present study adopts definitions of heritage sites from Matenga (2011) and the UNESCO convention (1972). The UNESCO convention (1972) defines heritage sites as a place, our legacy from the past, what we live with today and what we pass on to future generation. While Matenga (2011), defines the same aspect as an inheritance which is transmitted from generation to generation and this include tangible forms such as objects memorials and intangible forms such as cultural tradition. Both of these definitions cover the aspects of the present and future generations, while Matenga (2011) goes an extra mile to specifically include the invisible aspects associated with these sites. These definitions, therefore, helps in giving a broader understanding of the aims of this paper. Heritage sites in Zimbabwe are mainly dry stone walls and the Zimbabwean culture is arguably one of the most important developments in the last two millennia of Sub-Saharan prehistory (Maclver 1906; Caton- Thompson, 1931; Pwiti, 1996; Pikirayi, 2001; Chirikure et al 2013). Dry stone wall heritage sites in Zimbabwe have an important place consciously and unconsciously in the minds of every citizen, since the name of the country and that of the oldest capital city, Masvingo were driven from such heritage. Etymologically the word Zimbabwe can be regarded as a combination of a prefix and two Shona words i.e. Zi-imba-ibwe, while for Masvingo it's a prefix Ma and word -Svingo. In this regard prefix Zi refers to a very big thing, imba referring to a house and -ibwe referring to a stone/rock. Also "Ma" refers to the word "many" i.e. plural while "Svingo" literary means "A fortified place, a large and permanent fortification." These names have helped only the heritage practioners and a few outside this field in understanding the importance of these dry stone wall monuments as part of heritage. However for layman nothing much is known about connotations behind these names. According to Pwiti 
(1996) and Ndoro (2005) the dry stone wall heritage sites have two traditions which are the Great Zimbabwe and the Khami phase.

The Great Zimbabwe tradition dating around (AD1300-1450) and the Khami tradition around (AD1450-1650) after the relapse of the great Zimbabwe (Pikirayi 2001; Huffman 2009 e.t.c). Great Zimbabwe and Khami traditions have major differences which are that the ,former has many of free standing walls while the latter has retaining walls (Pwiti 1996; Chirikure et al 2013) see fig. 1 below. Freestanding walls are mostly common in the south central thus corresponding to the distribution of the Gumanye Great Zimbabwe-Karanga cluster, Leopard's kopje-KhamiKalanga area south western Zimbabwe (Chirikure et al 2013). The site under study in this research suits the description of the Great Zimbabwe/Zimbabwe tradition. 

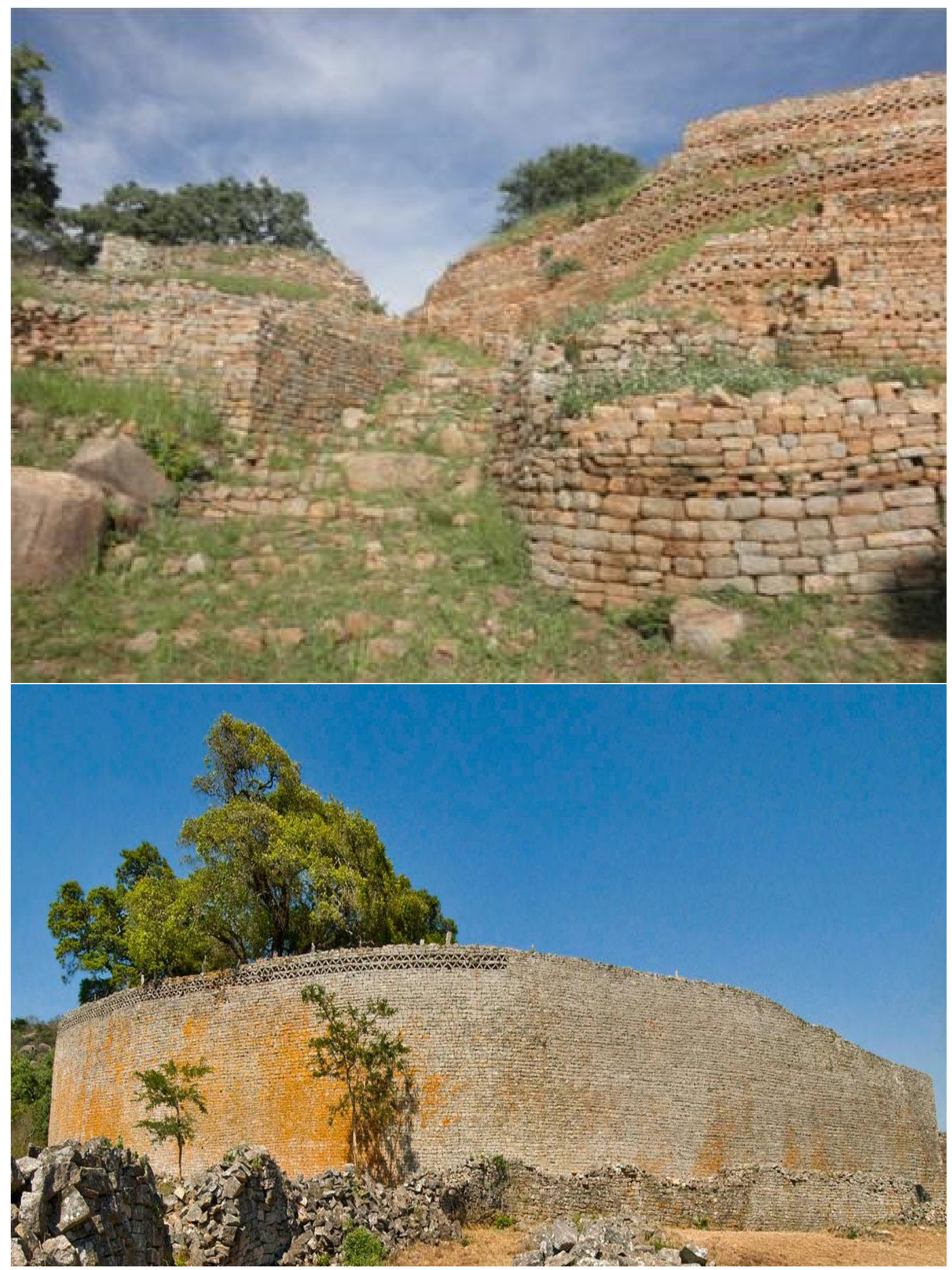

Fig 1: (Top) Retaining walls at Khami ruins (Credit: Chirikure et al 2013) and (Bottom) freestanding walls at Great Zimbabwe respectively. 


\section{Conservation of Heritage Sites}

The term conservation is derived from a Latin word conservare which means the preservation of the existing condition (Haper 2010). In the context of heritage sites conservation, includes all the processes of looking after a place so as to retain its significance, caring not only for cultural heritage values of the site but also the surrounding environment (Australia ICOMOS Burra charter 1999). Therefore conservation is a broad term which includes all processes of looking after a place, such as restoration and all acceptable management systems and strategies. In line with the aims of this paper, heritage conservation from the perspectives of restoration, community involvement and protection will be focused on.

\section{Introduction to Musimbira ruins, Zimbabwe}

Musimbira ruins is a dry stone walling structure on the northern edge of Bikita tribal land trust, $1 \mathrm{~km}$ South of Glen clova village (latitude 19॰59'02" S long 31॰26'25"E. see fig. 2). It is built on a low granite dwala surrounded by arable land with a high north-south ridge $300 \mathrm{~m}$ to its east. The ruin is located in a typical granite country, but contact with the schist of the Victoria (Masvingo), this schist belt is less than $1 \mathrm{~km}$ to the north near Glen Clova. The ruin occupy $60 \mathrm{~m}$ by $20-30 \mathrm{~m}$ and is comprised of five main stone enclosures. Although not much of the ancient workings have been confirmed, it should be pointed out that this part of the Schist belt comprises Bikita Tinfields (now Bikita Minerals). Bikita minerals is a mining company which started in 1950 as tin mining company but later shifted into lithium mining until present day (see Nolan 2013). Musimbira dry stone walling style confirms to the Q-style of Architect and contains nearly all the characteristics of phase IV in the Great Enclosure at Great Zimbabwe Summers et al (1961).

The site is dominated by freestanding walls which confirms that it's part of the Great Zimbabwe culture tradition dating between AD 1200 and AD 1550 (see Robison 1959; Chirikure et al 2013). Like most archaeological sites, Musimbira has a high surface distribution of broken pottery which has sadly however been exposed and damaged by local modern day subsistence farming activities.

In 1972, the first known excavations were done at Musimbira ruins by D.F Monro a former employee of the National Museums and Monuments of Rhodesia and C.W Spies with the motive 
of understanding the architecture of the ruin, therefore only a few areas were excavated. In one of the few trenches excavated, a juvenile skeleton with a copper bracelet on the right wrist and gold bangle around the neck was found. Also adding to the finds was a human skull was found on the corridor of one of the dry stone walled enclosures. Also a gold wire with a circumference of $12-14 \mathrm{~cm}$ and a gold necklace which was about $38 \mathrm{~cm}$ long with about $17-18$ coils per $\mathrm{cm}$ was found at this site. All these finds confirms to the presence of royalty within the site during it's existence (Monro and Spies 1975). Putting this site within the broader context with Great Zimbabwe one would suggest it to be either one of chief's residence or a base which helped initiate long distance trade with the Eastern coast. More study into this site and other similar small sites scattered along the far eastern part of Zimbabwe will do justice in giving a proper understanding of Great Zimbabwe and the Eastern coast trade area.

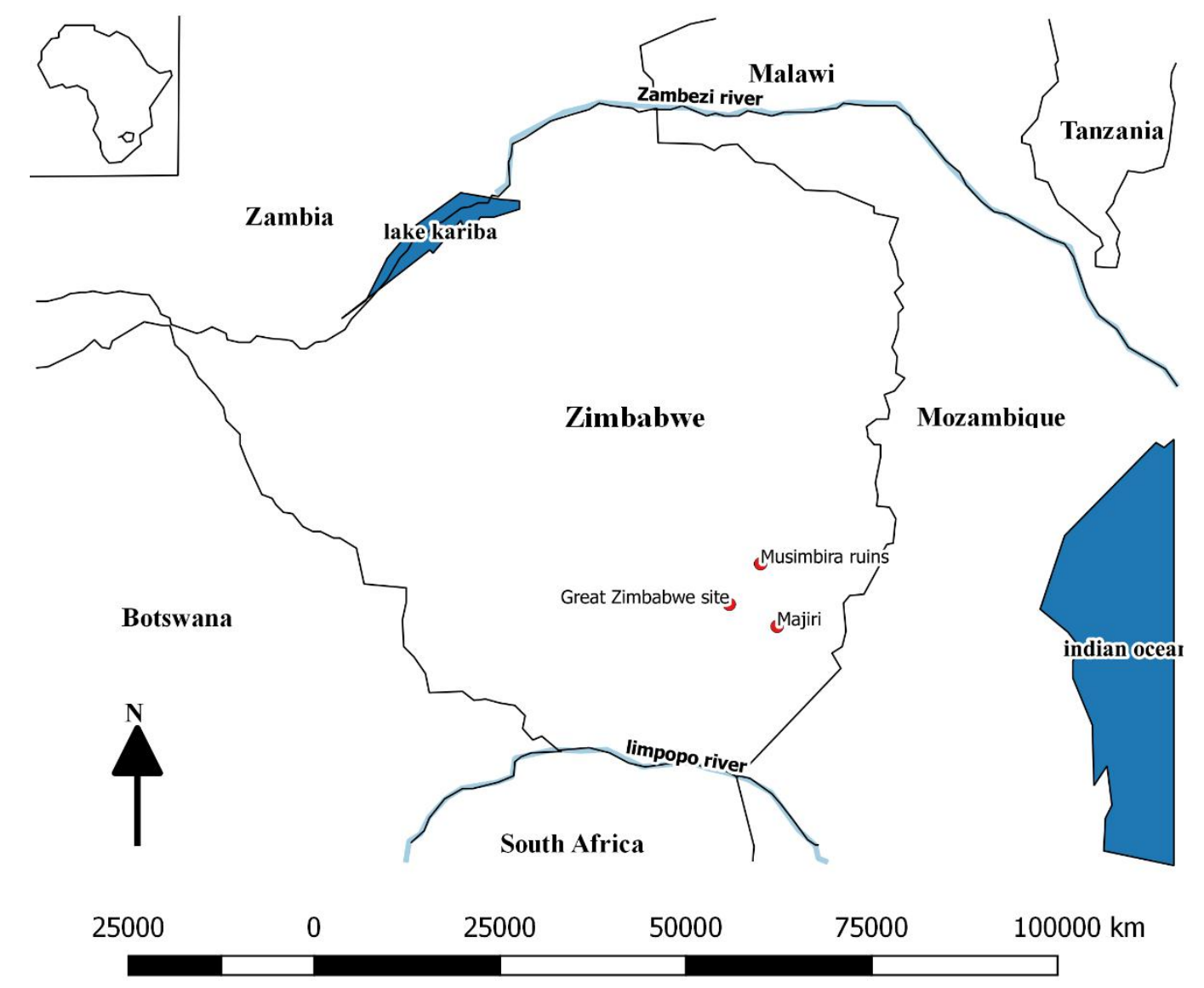

Fig 2: Map showing Musimbira and some of the dry stone walls in the Southern part of Zimbabwe including the largest in Southern Africa, Great Zimbabwe 


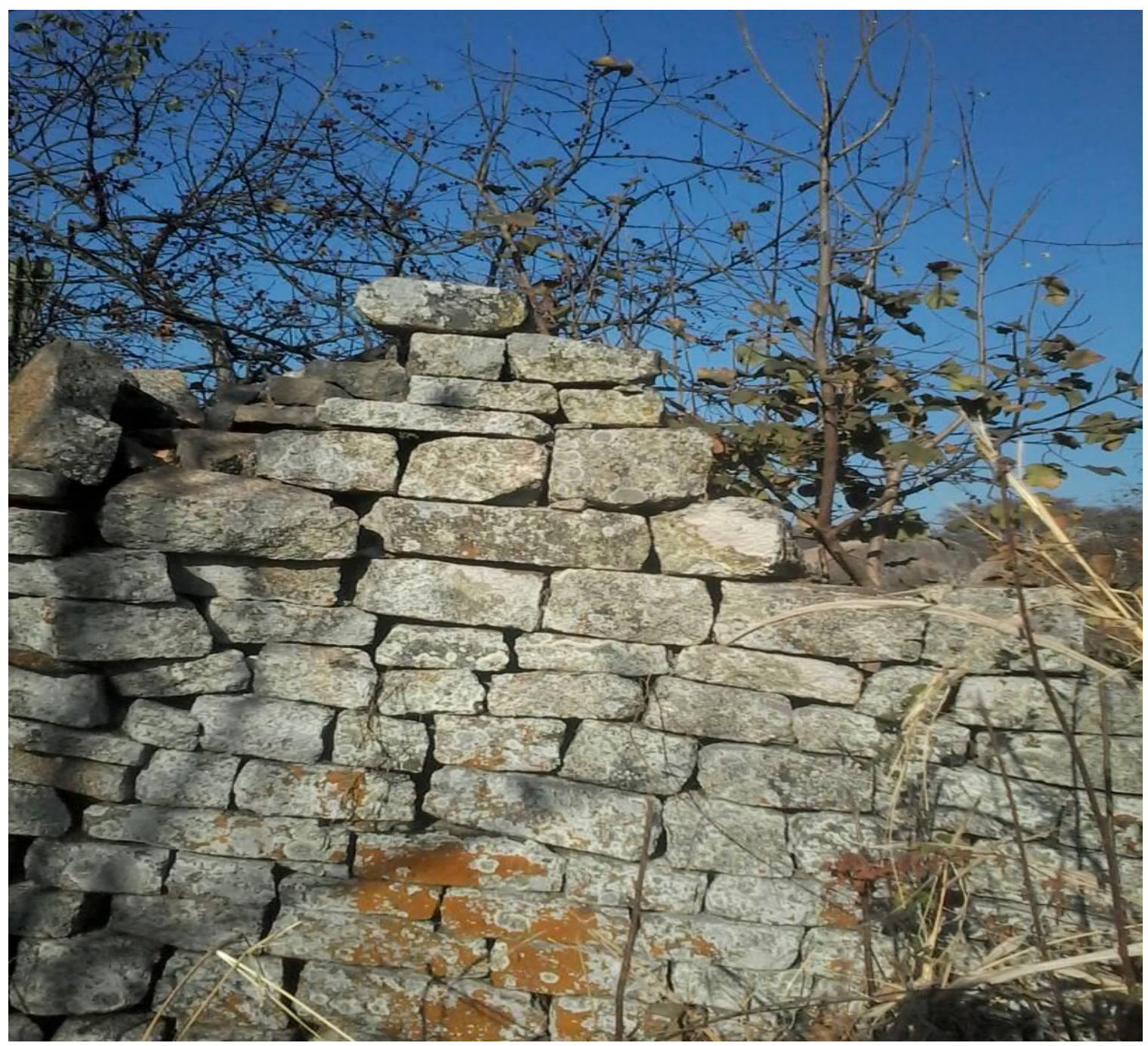

Fig 3: Photo showing Musimbira dry freestanding wall

\section{Heritage conservation at Musimbira}

From the $20^{\text {th }}$ century, heritage management at Musimbira was to some extent effective although with a narrow inclusion of the local communities who were being given some tokens of appreciation by the NMMZ (National Museums and Monuments of Zimbabwe). This is supported by the facts presented in a phone interview (11/09/17) with Mr. J.Chikutuva, a community member who obliged with NMMZ's directive to relocate a few meters away from the site. According to Mr. Chikutuva's statements during the 90s Musimbira site was fenced in order to prevent livestock invasion as well as giving a sense of security to the site. He also pointed out that the Bikita minerals mine officials (a local mining company $5 \mathrm{~km}$ north east of the 
site), made frequent visits to the site to enjoy its aesthetic view. This gesture according to the interviewed person was on one way or the other a conservation measure since this presented to the community the importance of the site hence encouraged them to have collective responsibility.

Frequent visits by the NMMZ, also helped in the conservation of the place since they were involved in the day to day site management. In another interview with Mr. Manyuchi (11/09/17), a community member who is also a worker at Bikita Mine, the area was associated with different unusual things. These included fire being seen at the site on different occasions, big snakes which did not harm anyone, such were conservation measures since a lot of people were respecting the area and some even feared to tamper around the area. Mr Chikutuva in a statement also pointed out during the evening the site was associated with unusual sounds of people singing and some drum beatings, that was around 1998, according to him. One of the community members (name withheld) also argues that Mr. Chikutuva's stay near the monument reduced some damages to the stone structures, since he was forbidding some locals from taking the granite stones to build their houses, kraals, and granaries and for other uses.

\section{Conservation problems at Musimbira}

Up to date it is surprising to note that, no conservation approach has been put in place at Musimbira since the year 2012. In a phone interview with Mr. Chikutuva (11/09/17), the NMMZ southern region team, where last seen at the site in 2012 and according to him their disappearance from their frequent visits was because they were frustrated by the lack of cooperation from the local community members. It should be well understood that the poor understanding of heritage sites by locals, is mainly a result of them being neglected their rights to participate in their heritage management. Such a view that locals should not be included in heritage management has resulted in detrimental effects, hence rampant cases of sabotage to the sites by the locals, knowingly and unknowingly since some members are at this point not even aware why they should conserve such areas. This conclusion was drawn from a focus group discussion carried out by the researcher in 2019. In this case of Musimbira, instead of the locals conserving the site they are however destroying it for their own perceived temporary "benefits". The fence which demarcated the site radius was stolen by the locals and used to fence gardens and to make animal traps. In an interview with some community members, the NMMZ, once 
served a verbal notice warning those within the site's radius to relocate to other areas, in 2010 .This measure was done in order to ensure that the site is left undisturbed. This however proved to be a major problem at the site since only a few cooperated. The village head (Mr. Mazhawidza) according to one community member, Mr Magocha (20/08/17 interview), was witnessed at some point in time through his man giving a notice that the site should be respected and no one should tamper around. Most people in this age are however not even aware of the importance as well as the stories behind the presence of the site at its current position and according to some community members the dry walls are just stones heaped without any importance to them.

Besides community activities, uncontrolled vegetation growth has been a contributing factor towards the deteriorating state of the site. Different species including lantana camara are growing within the dry stone walls causing significant wall collapse while also affecting the site's visibility.

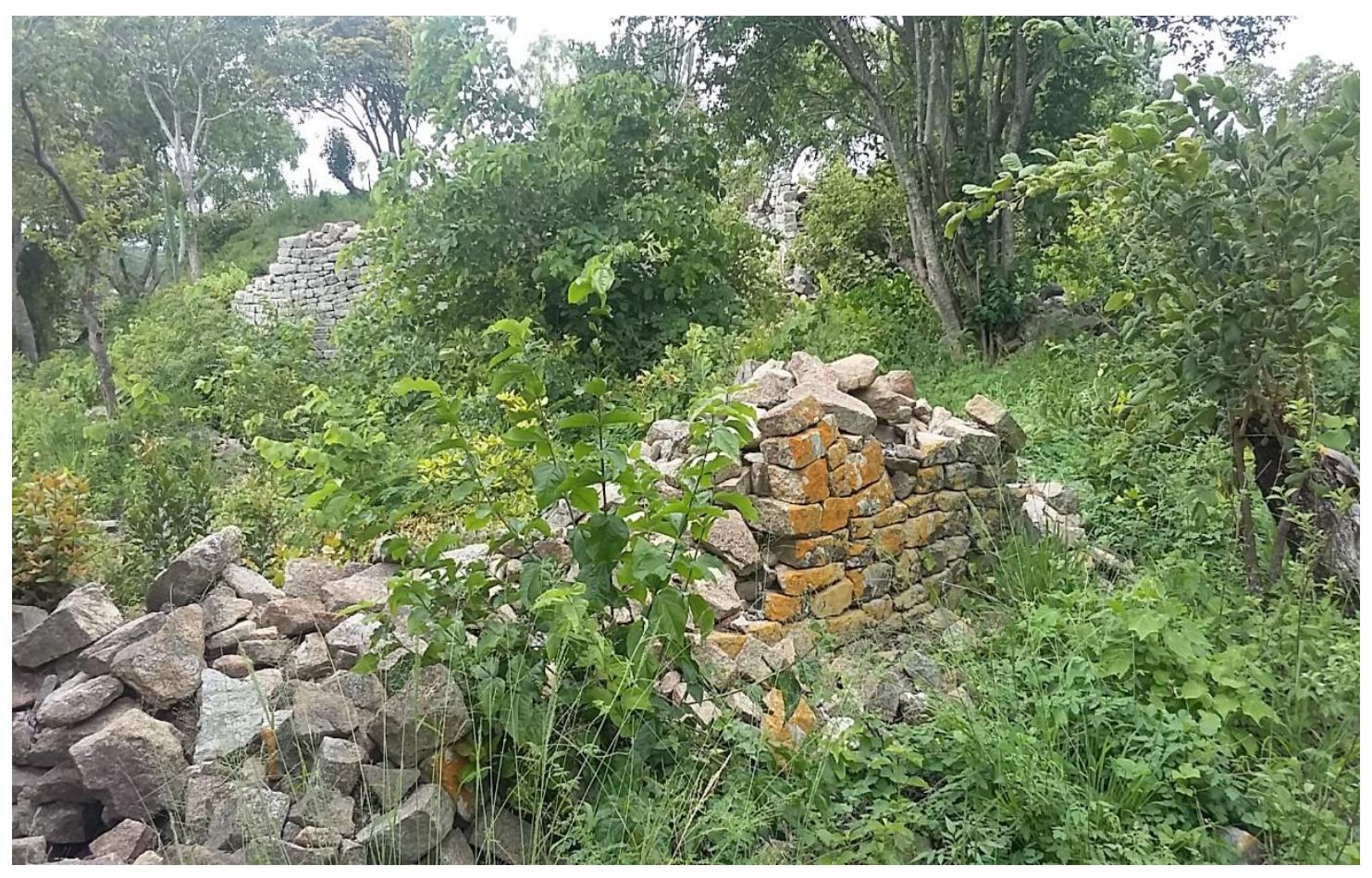

Fig 4: Photo showing dilapidated Musimbira dry stone wall covered by vegetation

Further conservation problems at this site have been exacerbated by modern farming and settlement activities. Recently a few meters, South western and eastern parts of the site, were turned into homesteads and crop farming land respectively (see fig $\mathbf{5}$ for a homestead). These 
unsustainable/incompatible activities at the site have heavily jeopardized the site's preservation. From an academic and research point of views these activities are similar to the burning of libraries, since a lot of crucial archaeological information which provides clues about our past is lost annually from this site. Having all said this it should be noted frankly that researchers in Zimbabwean archaeology will never fully understand bigger ancient capitals without working on smaller sites like Musimbira unless the archaeological researches are only in pursuit of personal biases/agendas.

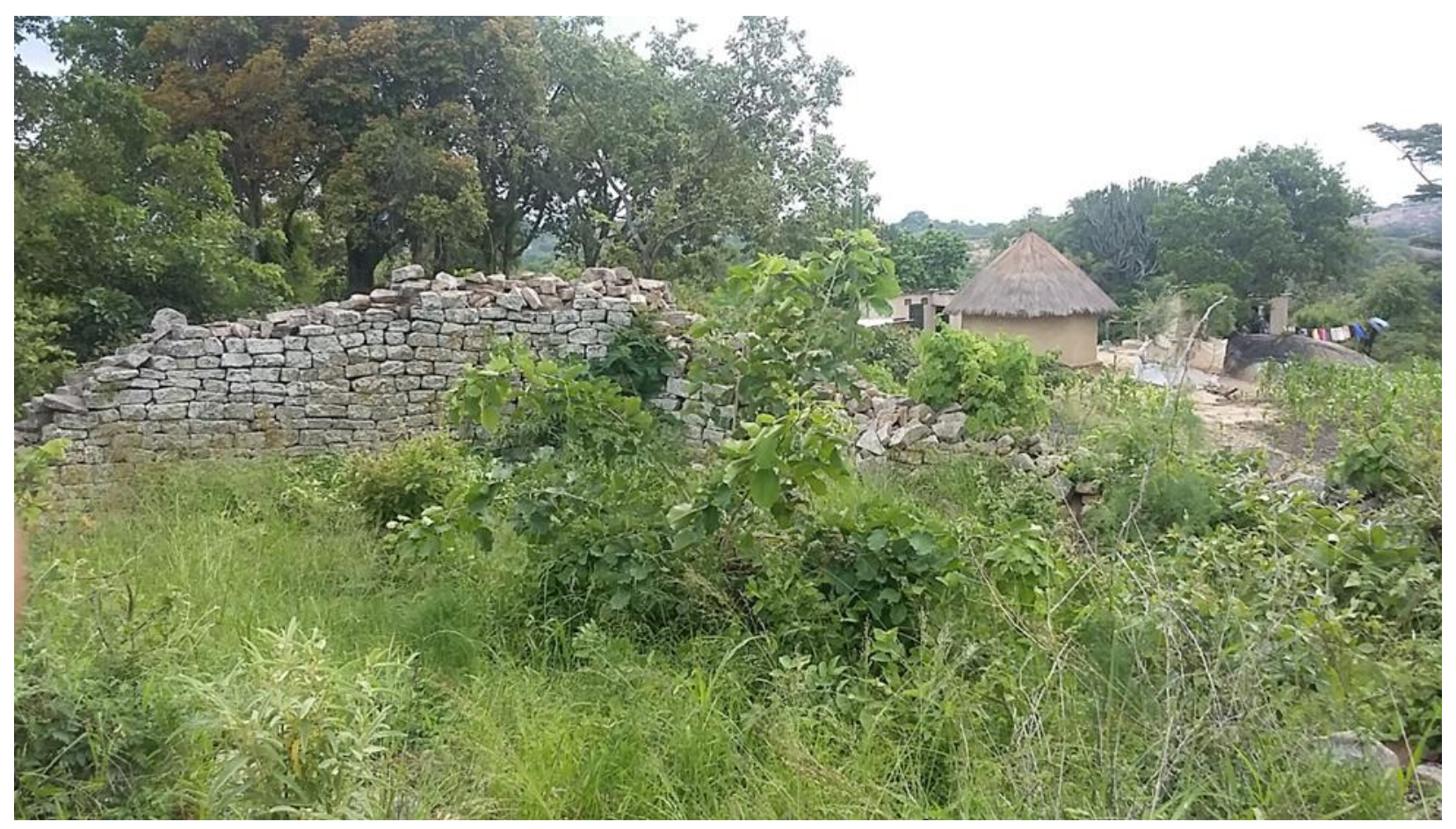

Fig 5: Showing the south western side a few meters from Musimbira site with a homestead

\section{Way forward to proper heritage management on Musimbira Ruins: Thinking with all Stakeholders.}

The way forward towards the protection and proper management of heritage, as noted by Mawere et al (2012), is to engage the community into the active participation rather than passivity in day to day management of heritage sites. Proper heritage management at Musimbira can be achieved in an atmosphere where all relevant stakeholders are involved in the decision making and implementation processes. Identifiable stakeholders include, the community at large, the chief (Marozva), headman, NMMZ, Bikita Minerals mine community, the nearby primary 
schools (Bikita minerals and Domboshava), Bikita Fashu high school. Bikita Fashu high school, a nearby school (3km away) was some time once in 2016 reported to have taken a class of junior history students to the site for an onsite lesson. According to one of the telephone interviews with Mr. Chikutuva, responsible authority, that is the NMMZ, should show their eagerness to protect the site, hence this will also result in the site having prestige and representation from the state.

An active community heritage committee should be appointed for a close management of the site and other archaeological heritage sites in the area. The articles 11,12,and 31 of the United Nations Declaration on human rights of indigenous peoples (United Nations 2007) clearly acknowledges the right of indigenous peoples to control properties and other matters related to their own heritage. According to Balme and Paterson (2014), this clearly shows that in order to ensure protection of sites, heritage practitioners should work in support of these human rights. As pointed out earlier in this paper communities should have a clear understanding of their heritage no matter how small. This understanding can be achieved through educational campaigns by various heritage practitioners and agencies on the importance and the management of the heritage sites. Educational campaigns can be achieved by special events which can be dedicated to the particular cultural heritage site. Apart from from the physical education strategies, social media can be used as a crucial tool in ensuring that heritage in it's various forms is known to it's owners through a more engaging strategy. This paper also suggests for archaeologists with interests to Southern Africa to priorities researches not only on major or highly built up sites but also to those unknown and small sites to ensure a balanced and proper understanding of our past.

\section{Conclusion}

This paper has revealed the state of heritage conservation and management at Musimbira dry stone wall site. Having managed to point out conservation problems affecting Musimbira, this study has argued for, the inclusion of all relevant parties to address the problems affecting cultural heritage properties. Therefore conservation being a broad term cannot be achieved only by one group of stakeholders but by different groups of active stakeholders where the local community is also recognized as key active players. 


\section{REFERENCES}

Australia ICOMS Burra charter, (1999). International charter for places of cultural significance. Australia ICOMOS. Australia.

Balme, J and Paterson, A. (2014). Archaeology in practice: A student guide to Archaeological analysis. John Wiley and sons Inc. New York.

Caton-Thompson, G. (1931). The Zimbabwe Culture: Ruins and reactions. Oxford: Clarendon

Chirikure, S and Pwiti, G. (2008). Community Involvement in Archaeology and Cultural Heritage Management: An Assessment from Case Studies in Southern Africa and Elsewhere. Current Anthropology 49(3), 468-485.

Chirikure, S., Manyanga, M., Pikirayi, I., Pollard, M. (2013). New pathways of social political Complexity in Southern Africa. African Archaeology review (2013) 30:339-366.

Collins English dictionary. (1994). Glasgow: HarperCollins Publishers

Huffman, T.N. (2009). Mapungubwe and Great Zimbabwe: The origin and spread of social complexity in southern Africa . Journal of Anthropological Archaeology, 28, 37-54.

Haper, D. (2010). Online etymology dictionary .https://www.etymonline.com.accessed 13/06/17.

Makuvaza S. (2014). Zimbabwe: Cultural Heritage Management. In: Smith C. (eds) Encyclopedia of Global Archaeology. Springer, New York, NY.

Mawere, M., Sagiya, M.E., Mubaya., T.R. (2012). Conservation conservations and community participation in the management of heritage sites in Zimbabwe. Greener Journal of environment Management and public safety.vol, 2(3) pp.007-016.

Matenga, E. (2011). The Soapstone Birds of Great Zimbabwe: Archaeological Heritage, Religion and Politics in Postcolonial Zimbabwe and the Return of Cultural Property. PhD dissertation, Department of Archaeology and Ancient History. Uppsala Universty, Sweden.

MacIver, D. (1906). Medieval Rhodesia. London: Routledge 
Monro, D.F and Spies, C.W (1975). Excavations at Musimbira, Bikita District, Rhodesia.

Arnoldia, Rhodesia.7 (22):1-11.

Ndoro, W. (2001). Your Monument our shrine: The preservation of Great Zimbabwe. Uppsala University. Uppsala.

Ndoro, W. (2005). Your monument our shrine: The preservation of Great Zimbabwe. Rome. ICCROM.

Nolan, G.H. (2013). Road to lithium lodge. Author House UK Ltd

Pwiti, G. (1996). Chiefs and Kings: A model of the development of cultural complexity in northern Zimbabwe. Zambezia 23, 31-52.

Pikirayi, I. (2001). Zimbabwe culture: origins and decline of southern Zambezian states. Walnut Greek: Alta Mira.

Phone interview with Mr. J Chikutuva 11 September 2017. Masvingo.

Phone interview with Mr. Magocha 12 September 2017. Masvingo.

Phone interview with Mr. Manyuchi 11 September 2017. Masvingo

Robinson, K.R., (1959). Khami Ruins. Cambridge: Cambridge University Press

Sagiya, M. E. (2019). Heritage on the periphery: administration of archaeological heritage in Hwange district, northwestern Zimbabwe. Journal of African Cultural Heritage Studies, Special Issue pp. 1-24.

Summers, R., Robinson, K. R., and Whitty, A. (1961). Zimbabwe excavations, 1958.

Occasional Papers of the National Museums and Monuments of Southern Rhodesia, Series (A), Human Sciences 3: 226-333

Thondhlana, T.P. and Machiridza, L.H. (2020). Restoration and Restitution of Cultural Heritage, the Case of the Ndebele Monarch: The Post-colonial Dilemma in Zimbabwe. Journal of African Cultural Heritage Studies, 2(1), pp.52-84. 
United Nations Education Scientific and Cultural Organization Convention of 1972. http://www.international.UNESCO.org accessed 20/06/17.

United Nations Declaration on human rights of indigenous people. (2007). Article11.United Nations.

United Nations Declaration on human rights of indigenous people. (2007). Article 12.United nations.

United Nations Declaration on human rights of indigenous people. (2007). Article 31.United nations. 